\title{
La in-visibilidad del protagonista del cambio en los procesos de formación docente. Las distancias entre el decir y el hacer
}

DOI: https://doi.org/10.32870/dse.v0i11.555

\author{
Ma. Guadalupe Valdés Dávila*
}

Resumen: En el presente artículo se presentan algunas consideraciones con respecto a los procesos formativos que se diseñan a propósito de que los docentes desarrollen las competencias profesionales que se requieren para la gestión del aprendizaje de sus alumnos, y con ello contribuyan al logro de la calidad educativa. Se reconoce que la tendencia de esos procesos se caracteriza por eliminar simbólicamente el conocimiento previo y la experiencia que como sujetos de carne y hueso han adquirido en su interacción con su medio familiar, institucional y social, y por ignorar el complejo mundo real donde se desempeñan. Modificar el pensamiento y acción de un profesor para que asuma los rasgos que se necesitan para la implementación exitosa en las aulas de los nuevos modelos y enfoques derivados de la decisión política implica, además de reflexiones críticas, importantes virajes en las experiencias formativas para que no sólo sean congruentes y consistentes con los propios principios que abanderan, sino adaptables y ajustables al saber, a la experiencia del docente y al contexto en donde desarrolla su práctica educativa. Palabras clave: política educativa, cambio, depósitos de sentido educativo y formación docente.

\begin{abstract}
In the present article presents some considerations with respect to the formation processes that are designed to purpose that teachers develop professional skills that are required in the management of their students' learning and thus, contribute to the achievement of the educational quality. Even today, it is recognized that the trend of those processes that are geared to train them in the distinctive characteristics of the models focusing on the apprentice that are driven from the educational policy, is characterized by delete symbolically the prior knowledge and experience that as subjects of flesh and blood have acquired in their interaction with their family environment, institutional and social, and to ignore the complex real world where you play. Modifying the thought and action of a teacher to take the desirable traits that are needed for the successful implementation in the classrooms of the new models and approaches derived from political decision, implies in addition to critical reflections, important turning in the formative experiences so that not only are relevant and consistent with the principles themselves that register the discourse of educational change, but adaptable and adjustable to knowledge, in the experience of the teacher and the context where develops his educational practice. Keywords: educational policy, change, deposits of educational sense and teacher training.
\end{abstract}

\section{El contexto del cambio y el viraje en los sistemas educativos}

Una administración educativa caracterizada por el centralismo, una oferta homogénea de servicios para poblaciones heterogéneas y procesos educativos centrados en la enseñanza más que en el aprendizaje, son algunos de los antecedentes clave que en la década de los ochenta, además de mostrar el agotamiento de una concepción y estilo de desarrollo educativo que dejaba ver su incapacidad para conciliar el crecimiento cuantitativo con los niveles esperados de calidad, per-

* Doctora en Educación. Académica del Departamento de Psicología, Educación y Salud en el Instituto Tecnológico y de Estudios Superiores de Occidente. Periférico Sur Manuel Gómez Morín 8585, Tlaquepaque, Jal. Cel.: 33160178 87. Correo electrónico: pitina@iteso.mx 
miten entender por qué en los últimos 30 años los sistemas educativos impulsan modificaciones importantes en el aspecto institucional y pedagógico del modelo educativo. La IV reunión del Comité Intergubernamental del Proyecto Principal de Educación, celebrada en Quito en 1991 con el propósito de lograr una educación de mayor calidad que diera respuesta a los desafíos de la transformación productiva, la equidad y la democracia, marca un punto de inflexión importante en el desarrollo educativo. La satisfacción de los requerimientos básicos de aprendizaje de los alumnos implicaba una nueva visión de la educación más centrada en el aprendizaje que en la enseñanza y por lo mismo un currículo que superara al enfoque basado en disciplinas que prevalecía en la década de los ochenta (UNESCO, 1998).

En la década de los noventa diferentes países de América Latina, entre ellos México, inician una nueva etapa de transformación con una perspectiva renovada del modelo educativo. Sin descuidar la extensión, los esfuerzos de los sistemas se orientan hacia cambios cualitativos, en especial incorporan una visión de la educación más centrada en el aprendizaje que en la enseñanza, lo que supone entre otras cuestiones que el estudiante dirija sus propios proyectos, trabaje a su ritmo, se entusiasme con el aprendizaje, interactúe colaborativamente y participe de manera proactiva, a partir de las ayudas estratégicas que el profesor le ofrezca, a fin de construir significado relevante y pertinente de lo que aprende. Situarse en clave del aprendizaje representa para el docente el diseño de situaciones estratégicas que ofrezcan a los alumnos diversas y múltiples oportunidades, y mayores responsabilidades para que identifiquen sus propias necesidades, ubiquen los recursos de aprendizaje que necesitan y construyan conocimiento útil.

Transitar de la enseñanza al aprendizaje es un cambio que por decreto político los docentes han de realizar. Como dice Hargreaves, en las épocas de crisis económicas y de gran competitividad se produce un pánico moral ante la forma de preparar a las generaciones del futuro y por lo mismo es que se prevé que las escuelas en general y los profesores en particular contribuyan a la resolución de los grandes problemas de las sociedades y para hacerlo han de participar en la dirección que espera un mercado global en franca expansión (Hargreaves, 1999: 37).

Estos cambios educativos en el ámbito discursivo presentan múltiples bondades, pero asumirlos, encarnarlos en la vida de las aulas representa un verdadero reto y una enorme dificultad. El cambio educativo puede ser preciso, relativamente fácil y rápido cuando se reduce a los aspectos estructurales del diseño de la política curricular, pero la transformación a profundidad de los procesos educativos en el aula en lo cotidiano del día a día resulta mucho más compleja.

El saber previo de los docentes y su papel en la lectura e interpretación de las aspiraciones que conlleva el cambio educativo

La concepción de aprendizaje significativo que el teórico norteamericano Ausubel (1983) ofrece al mundo de la educación en los años setenta del siglo XX, constituye un referente importante para entender qué pasa cuando se deja de lado el saber previo de los profesores, sus deseos, necesidades 
o sus resistencias por abandonar lo que consideran valioso y útil en su práctica educativa. Si bien las autoridades educativas tienen expectativas para que los profesores a partir de las propuestas de formación que tienden a utilizarse como dispositivos en la retórica del cambio, se apropien del mismo y lo hagan realidad en cada aula del país, resulta conveniente, como lo señala Díaz Barriga (2010), que al menos se cuestionen qué y cómo aprenden y qué es lo que les impide cambiar o no en sus prácticas, en otras palabras, dilucidar el sentido y significado que en este caso tiene el modelo educativo centrado en el aprendizaje como eje estructurante de toda práctica educativa.

Este constructo aportado por Ausubel puede ayudar a mirar y a entender el proceso a través del cual el profesor relaciona la nueva información con su conocimiento previo, es decir con ideas, conceptos o proposiciones disponibles en su estructura cognitiva, pues como bien se sabe, funciona como punto de anclaje del nuevo conocimiento. Desde este aporte resulta bastante claro que al igual que los alumnos, las mentes de los profesores de los distintos niveles educativos no constituyen pizarras en blanco, pues a través de procesos educativos-sociales, formales e informales han construido una serie de conocimientos con respecto a lo que significa el aprendizaje, la enseñanza, el alumno y el profesor, así como de los fines sociales de la educación escolarizada. Este bagaje de conocimiento y experiencia en tanto conglomerado de significados, al ponerlo en relación con el modelo educativo cuyo énfasis es el aprendizaje, puede dar lugar a una diversidad de lecturas, significaciones y por lo mismo acciones en la práctica educativa que no necesariamente resultan coincidentes con los acentos del nuevo modelo que por decisión política han de encarnar en la vida de las aulas.

A partir de la significación que hace cada docente se puede comprender que sus acervos de conocimiento que tienen a mano - aún después de haber participado en distintos procesos de formación - pueden no resultar compatibles con el significado que se perfila en la nueva apuesta educativa. Así como habrá concepciones de los profesores que remiten a vivencias de ajenidad que implican lejanía, confusión e incoherencia con los significados implicados en la nueva pauta cultural, habrá otras que por ese basto depósito de sentido educativo que han construido en su paso por las distintas fases de formación, también muestren los distintos significados construidos acerca de los alumnos, de lo que consideran importante en su formación, de los conocimientos que para ellos son valiosos y de cuál es la mejor manera de enseñar, evaluar, motivar, etcétera.

La variabilidad de significados depende de esas teorías explícitas e implícitas que han construido; por ello, para unos el aprendizaje se relacionará con condicionamientos, mientras que para otros con adquisición de información, cambio de conducta, uso de conocimientos en la resolución de problemas, construcción de nuevos significados, etc. Con base en estas ideas es que se afirma que no hay un significado unívoco ni homogéneo con respecto a la conceptualización e implicaciones del modelo educativo en cuestión, sino heterogeneidad de significaciones y por lo mismo variabilidad en los modos de entender y asumir lo educativo. La metáfora de Borges (1999), "nunca un mapa puede ser exactamente igual al territorio que representa", coincide con la idea de Pozo (2013) 
en cuanto a que toda representación es una construcción que genera nuevos mundos, nuevas formas de conocer, que no se limita a recoger el orden externo, sino a generar nuevas formas de organización, en suma nuevos significados. En este tenor, resulta bastante comprensible que el significado que le atribuyan al modelo de aprendizaje centrado en el aprendiz, sea un reflejo del conocimiento construido por el profesor y no al revés, como suponen los que diseñan y promueven procesos de formación docente, quienes aún se empeñan en ignorar los vastos depósitos de sentido educativo que ha construido el docente en sus trayectos de vida personal y profesional.

A pesar de los diferentes cambios que se dirigen desde la actual política curricular, existen docentes y profesionales de la educación que están convencidos de que los alumnos aprenden si están en silencio, escuchando, observando atentamente y repitiendo ejercicios variados que los ayudarán a transferir ese conocimiento a situaciones de vida cotidiana. Asimismo habrá otros que aún se consideran la autoridad en el grupo, en tanto son los encargados sociales de transmitir de maneras diversas los contenidos elaborados y predeterminados de antemano. En esta diversidad de concepciones aún se reconocen profesores que están convencidos de que la evaluación es un procedimiento que se usa al final de un mes o bimestre para comprobar si el alumno aprendió o no el conocimiento correspondiente. A partir del lenguaje de los hechos se puede apreciar que existen profesores que continúan apegados a una racionalidad diferente a la que lleva aparejada ese cambio educativo y otros que no prestan tanta atención a los contenidos escolares y dan paso a la experiencia natural y social que rodea al alumno.

Para mostrar el papel que juega el saber previo en la manera en que se significa lo nuevo, y que por lo general tiende a ser pasado por alto en los programas de formación, se hace uso de la observación que Hargraves y Fullan (2014) retoman de la obra "escuelas de bajo rendimiento" de Richard Ellmore: "Las colaboraciones entre el profesorado se centran en la pasión y en el entusiasmo por la enseñanza en lugar de la evidencia de lo que realmente aprenden los alumnos". Con este ejemplo se puede advertir que el aprendizaje centrado en el aprendiz como modelo guía de la práctica de estos profesores aún no adquiere derecho de realidad, pues pese a las directrices de la política curricular y a la formación en la que participaron con su respectiva mediación, su atención continúa anclada en la tarea de enseñar.

$\mathrm{Al}$ reconocer entre otras cuestiones que las concepciones de los docentes son el antecedente clave desde donde leen, interpretan y operan por así decirlo la nueva propuesta de cambio con su respectivo modelo educativo, se advierte la existencia de una multiplicidad de significaciones con respecto al modelo de aprendizaje centrado en el aprendiz y no significados unívocos y homogéneos que esperan los reformadores del cambio. Esta variabilidad, se quiera o no, interfiere para bien o para mal en el aprendizaje de los alumnos que se pretende privilegiar, pues como ya se ha dicho habrá profesores que consideren que la enseñanza es un don y una virtud, un saber práctico, un catálogo de técnicas y actividades que se pueden prescribir con facilidad, un saber teórico o un proceso complejo que implica aprendizajes continuos, etcétera. 
En esta misma tesitura de la multiplicidad de significados, Esteve (2003) hace un reconocimiento explícito de la existencia superpuesta en las escuelas de al menos cuatro modelos educativos, lo que implica que distintos colectivos esperen cosas diferentes de la educación y por lo mismo que sus enfoques se encaminen hacia distintos propósitos y fines. Esas concepciones, creencias, conocimientos, valores y actitudes que sintetiza con el nombre de "esquemas de pensamiento y acción" las agrupa en las siguientes tipologías:

* Modelo de la educación como molde. Los adultos definen las metas, objetivos y contenidos básicos que deben aprender los alumnos. El papel asignado al aprendiz consiste en dejarse moldear por la experiencia acumulada del adulto, quien puede quedar satisfecho cuando observa y comprueba que los niños y jóvenes son capaces de repetir lo que se les ha inculcado. Los errores se corrigen y hasta se castigan cuando su conducta es incorrecta, en tanto no se apega al canon establecido.

* Modelo de educación como enseñanza. El profesor sólo se ocupa de la formación intelectual del alumno a través de la enseñanza de las materias de estudio. La instrucción es tarea de las escuelas y la educación (valores morales, principios cívicos y cuestiones estéticas) responsabilidad de las familias.

* Modelo de educación como libre desarrollo. Desde esta cosmovisión se evita el castigo y la represión. El alumno es quien debe descubrir el mundo por sí mismo y elaborar sus propias ideas con respecto a los valores y las normas morales.

* Modelo de educación como iniciación. Esta visión trata de adaptarse a un mundo pluralista y democrático. El profesor no impone al alumno lo que tiene que pensar, creer o hacer, sólo los inicia en los valores que la humanidad considera valiosos pero sin imprimirles finales predeterminados que el aprendiz tenga que aceptar. La iniciación consiste en un proceso mediante el cual se ilusiona al que aprende para que se adentre en un campo nuevo, descubriendo la realidad desde una nueva perspectiva. Este modelo busca un equilibrio entre el rechazo de la imposición y la aceptación de la influencia (Esteve, 2003: 123-151).

El conglomerado de ideas más o menos estructuradas en cada uno de esos modelos ayuda a dejar en claro la variabilidad de conocimientos previos que pueden tener los profesores con respecto al qué, para qué, por qué, cómo, cuándo y dónde de lo educativo, y por supuesto a entender que este conocimiento se constituye en el fundamento desde donde se acercan a leer, comprender y construir significado con respecto al nuevo modelo educativo que está presente en los actuales enfoques curriculares y que, como ya se ha dicho, colocan al estudiante y al aprendizaje en el centro del proceso formativo.

Cada uno de estos modelos expresa una manera particular de entender el aprendizaje y, por lo mismo, tomas de posición y decisión respecto a los elementos que incluyen o excluyen del proceso educativo. El profesor, al identificarse con tal o cual modelo, o con hibridaciones de elementos que puede tomar de los diferentes enfoques, establece una jerarquización de valores, una particular 
relación teoría-práctica, determinada posición para cada uno de los actores implicados y para las modalidades de interacción con el objeto de aprendizaje, con los compañeros del grupo y con el propio docente (Vezub, 2006).

Al tener en claro que no es posible dar la espalda a los saberes previos de los profesores, se ha de reconocer que existen distancias en cuanto a la cercanía o lejanía de este bagaje con respecto a las ideas clave que están presentes en el nuevo modelo. A este respecto, Valdés (2013) señala que la cercanía, la familiaridad y la claridad conllevan a una mayor aceptación por parte de los profesores del contenido del cambio como nueva pauta cultural, ya que sin esas dimensiones esenciales los profesores tienden a caminar erráticamente, puesto que cada quien lo hace guiándose por el conocimiento de receta a mano y no por el que se determina desde la política curricular. La dificultad o la posibilidad para cambiar hacia otra cosmovisión depende del contenido de conciencia, en otras palabras, de los saberes previos de los profesores. Si la distancia y la congruencia entre lo que sabe y lo que se quiere que aprenda son adecuadas, las posibilidades para establecer relaciones significativas entre lo previo y lo nuevo aumentan. Como lo dice Pozo (1987), esas ideas previas conforman una conspiración cognitiva que ayuda o dificulta la comprensión y la significación de lo nuevo.

\section{Las características que prevalecen en los modelos de formación docente}

La teoría del aprendizaje significativo de Ausubel (1983) no limita su uso al aprendizaje de los alumnos, puesto que el elemento central del proceso de construcción de significados también resulta ser un constructo potente en la formación inicial y continua de los profesores. Aunque a estas alturas resulte impensable que se siga insistiendo en propuestas formativas que aún conciben a la formación como un sistema de elaboración de productos en serie, al estilo taylorismo o fordismo, Brigin (2006) y Vezub (2010) advierten que al menos en la década de los noventa, y en los primeros años del siglo XXI, en los modelos usados como dispositivos vinculados al fortalecimiento de las competencias y de la profesionalidad del docente subyace la idea de profesores deficitarios e ineficaces, que carecen de los conocimientos y herramientas adecuadas para la enseñanza que se necesita, por ello un conjunto de expertos es quien se encarga de seleccionar los temas y contenidos desde una visión centralista y homogénea. En esta misma tesitura, Southwell (2006) sostiene que la reforma educativa de los noventa instaló un discurso público en el que se reconocía que los docentes no sabían. Lejos de valorar sus saberes y experiencias, se les desacreditó, lo que en palabras de esta autora contribuyó a forjar en los padres, alumnos y en la sociedad en general una imagen social devaluada del docente.

De lo que se trata es que los profesores, mediante las modalidades de cursos y talleres masivos y de corta duración, adopten los contenidos de ese cambio y los apliquen en las aulas, sin que en ello se considere que su forma y estilo de enseñar tiene su base en sus orígenes, en su biografía, en el tipo de profesor que cada uno ha llegado a ser y por supuesto en los significados que atribuyen al modelo. 
La in- visibilidad del protagonista del cambio en los procesos de formación docente. Las distancias entre el decir y el hacer

Los de afuera gestan movimientos, planifican contextos y situaciones para que el docente se forme a imagen y semejanza de aquellas ideas que desde su punto de vista mejorarán y enriquecerán los procesos educativos. Los autores intelectuales aparecen como titiriteros que al montar los telones y jalar los hilos harán que la marioneta ipso facto se mueva ante el ritmo que marca el cambio, transformación o mejora (Valdés, 2009: 63).

Valdés manifiesta que esas coordenadas que han intentado señalar los nuevos movimientos de cambio en los sistemas de enseñanza no consideran que los docentes han construido y enriquecido, con cada experiencia y situación en las que han participado, depósitos de sentido educativo; éstos actúan como filtro desde el cual se lee e interpreta todo aquel material simbólico con el que teje la estructura y el contenido de esa reforma (Valdés, 2009: 67). La voz del docente, al seguir siendo soslayada e ignorada, muestra que el discurso político que los ubica como actores y protagonistas del cambio queda en quimera, puesto que los hechos hablan más que mil palabras. El mismo Hargreaves (1999) considera que el trato que reciben los profesores en los procesos de formación se asemeja al que se le ofrece a los alcohólicos mediante los planes de desintoxicación; tienen que someterse a métodos de instrucción que avanzan paso a paso o que acatan pruebas y currículos preestablecidos y cerrados para ser eficaces.

Lo que resulta más inverosímil de los actuales modelos de formación es que el enfoque centrado en el aprendizaje tienda a reservarse para los alumnos de estos profesores y no se use como una estructura de sentido en la formación de quienes están llamados a enseñar desde esta cosmovisión educativa. Para Torres (1999), las instituciones y los programas de formación docente han sido la mejor "escuela demostrativa" de la racionalidad técnica, es decir, de la escuela transmisora, autoritaria y burocrática que desdeña el aprendizaje. Al parecer la eficiencia y productividad prometida en la modernidad desde la cual se crearon procesos laborales que separan la gestión de la docencia, la planificación de la ejecución y por qué no decirlo, la cabeza de la mano, en donde las tareas se separan en componentes mesurables, haciendo que el trabajo docente pierda cualificación, continúa teniendo un lugar privilegiado en los procesos formativos que en la actualidad se siguen promoviendo para que el docente cambie, pero sobre tradiciones que construidas históricamente se mantienen en estos tiempos de "cambio educativo".

¿Se podría hablar de aprendizajes significativos por parte del docente, cuando sus saberes previos se in-visibilizan y las políticas en materia de formación tienden a no tomar en cuenta la centralidad de su aprendizaje?; ¿se les podría pedir que realicen en sus aulas, lo que no ven aplicado en su formación?; ¿que abandonen el paradigma de la enseñanza, cuando éste es el que predomina en su formación profesional?; ¿que organicen el aula de tal manera que atienda la diversidad, cuando la homologación, la homogenización y la masificación son rasgos que se han institucionalizado en los espacios formativos?; ¿que logren concretar las aspiraciones y deseos de la política sin experimentar conflictos a partir de las realidades contextuales y estructurales de las propias escuelas? 


\section{A manera de conclusión: lecciones de aprendizaje que deja la experiencia en materia de formación docente}

Con el reconocimiento de la coexistencia de múltiples significatividades que construyen los profesores del modelo educativo del aprendizaje centrado en el aprendiz en función de sus conocimientos previos, vale la pena resaltar las siguientes cuestiones, pues la transformación que se quiere del docente no se logra mediante la decisión política y menos con el uso de modelos formativos que a todas luces muestran un agotamiento:

* Ante marcos de referencia diferentes, se producen interpretaciones y realidades múltiples que muchas de las veces se juzgan implacablemente porque no necesariamente coinciden o se ajustan a lo que espera el lenguaje colonizador en vigencia.

* Ante el desajuste que hay entre lo que se legitima desde un nuevo modelo y los procesos-resultados de determinada práctica educativa, se cae fácilmente en la tentación de poner una y otra vez en el banquillo de los acusados al profesor, pues la efectividad no llega a apreciarse en el nivel de los concretos.

* La importancia que tiene el evitar la promoción de la frustración y el desánimo de los profesores ante una continua deslegitimización de sus saberes y experiencias que son valiosas por su efectividad, pero que por una u otra razón no encajan en el marco conceptual y operacional que ofrece el nuevo modelo.

* La posibilidad de colocar al nuevo modelo en la categoría de la prescripción técnica, en tanto se le limita al profesor a buscar estrategias alternativas dentro de las fronteras que establece el propio modelo, sin ofrecer una mayor libertad para que explore otros territorios ajenos y diferentes al que ofrece esta cartografía del aprendizaje. No se trata de poner en duda las oportunidades, ventajas y posibilidades que puede ofrecer el modelo, sino de invitar al docente a que en y desde su experiencia en la práctica, participe en su escrutinio y reflexión para que desde ahí reconozca y muestre sus límites, contradicciones, ventajas y posibilidades.

* Evitar el riesgo de venerar idealmente al modelo sin tomar en cuenta la complejidad que se vive en las aulas, precisamente por todas las variables ahí presentes, incluyendo el saber previo del profesor y su propia significación con respecto a la nueva ecología del aprendizaje. El docente "real" que está en las aulas puede ser bastante diferente del docente ideal que se proyecta a nivel del modelo.

* Entender que un cambio que se impulsa a través de un determinado modelo educativo no sigue una sola trayectoria ni un mismo tiempo para su recorrido, pues cada docente la proyecta y la transita en función de los elementos contextuales y de los saberes previos, que como ya se ha dicho, configuran un modo particular de significación y por lo mismo un significado específico en la práctica educativa.

* Pensar cambios en los estilos y modos con los que se tiende a proyectar la formación de los docentes, en los cuales, como ya se ha dicho, es bastante factible que se deje de lado el alto valor que tiene el poder y pensamiento crítico del docente, equivale a seguir caminando erráticamente. Aunque con los programas de formación se intente acortar las brechas que hay entre la situación deseada y la existente, este deseo puede fracasar precisamente porque sólo se tiende a privilegiar el punto de llegada, obviando el de partida. Necesariamente el deseo de un nuevo rol docente ha de llevar aparejado un nuevo modelo de formación, congruente y consistente con esas consignas del cambio. 
La in- visibilidad del protagonista del cambio en los procesos de formación docente. Las distancias entre el decir y el hacer

\begin{abstract}
* Empoderar al docente para que asuma un papel de agencia, pues no hay que olvidar que a nombre de la generalización de la ciencia con sus respectivos controles persiste la tendencia a colocarlo en el papel de técnico de la educación. Kincheloe (2001) señala que ante toda posibilidad de conferir poder al profesor, se requiere de la re conceptualización de sus conocimientos, pues esto permite que con base en ellos y sus experiencias prácticas pruebe, compruebe, valide, enriquezca o niegue aspectos centrales del nuevo modelo educativo.

* El coste de in-visibilizar los atributos relevantes que forman parte del bagaje de los conocimientos del docente y el juicio profesional en su desempeño es alto, en tanto no sólo condiciona los procesos de cambio sino que los hace inviables, precisamente por las contradicciones que muestran entre las finalidades proclamadas y las acciones efectuadas. Relegar al docente en el diseño de programas de formación, desconocer su experiencia acumulada y sus depósitos de conocimiento educativo puede significar tal y como nos muestra la historia de la educación, un continuum de fracasos que intentarán resolverse nuevamente con renovadas ideas que al fin de cuentas no tardaran en convertirse en lenguaje muerto (Valdés, 2009). Los modelos de formación, por más buenas intenciones que contengan, pueden desvirtuarse cuando desconocen al docente como un sujeto de carne y hueso y por lo mismo su diversidad cultural, que se supone es una de las bases de la construcción pedagógica que tanto se alienta a nivel del discurso reformador. En este orden de ideas Gimeno (1999) señala que en la posmodernidad, en tanto condición de los tiempos que toca vivir, no hay lugar para utopías cerradas que profetizan un tipo humano nuevo y una sociedad ideal, pues al ser estáticas aniquilan la individualidad a nombre de la homogenización.
\end{abstract}

Al reconocer que la calidad educativa está estrechamente relacionada con una mejor formación docente, es que se señala la necesidad y urgencia de construir escenarios de debate y reflexión crítica que favorezcan la construcción de políticas de formación más integrales y abiertas; políticas que entre otras cosas, capitalicen los aprendizajes que han dejado la ola de implementaciones de enfoques, principios y conceptualizaciones que forman parte de las grandes tradiciones dominantes en materia de formación que, como ya se ha dicho, relegan al que se supone es el protagonista del cambio. Ceñir la formación a la vorágine del cambio y a los valores universales que se proclaman en los discursos políticos equivale a seguir perpetuando la inoperancia de los sistemas educativos.

\title{
Referencias bibliográficas
}

Ausubel, D. (1983). Teoría del aprendizaje significativo. Recuperado de: http://www.educainformativa.com/ar/docentes/artículo/educación/ausubel

Birgin, A. (2006). Pensar la formación docente en nuestro tiempo, en: Terigi, F. (comp.). Diez miradas sobre la escuela primaria. Buenos Aires: Siglo XXI.

Borges, J. L. (1999). El hacedor. Madrid: Alianza Editorial.

Díaz-Barriga Arceo, Frida (2010). "Los profesores ante las innovaciones curriculares", en: Revista Iberoamericana de Educación Superior (RIES), México: IISUE-UNAM/Universia, vol. 1, núm.1, pp. 37-57. 
Esteve, J. (2003). La tercera revolución educativa. La educación en la sociedad del conocimiento. Barcelona: Paidós.

Gimeno, J. (1999). "La educación que tenemos, la educación que queremos", en: Imbernón, F. (coord.). La educación del siglo XXI: los retos del futuro inmediato. Barcelona: Graó.

Hergreaves, A. (1999). Profesorado, cultura y posmodernidad. Cambian los tiempos, cambia el profesorado. Madrid: Morata. y M. Fullan (2014). Capital profesional. Madrid: Siglo XXI.

Kincheloe, J. (2001). Hacía una revisión crítica del pensamiento docente. Barcelona: Octaedro.

Pozo, I. (2013). Adquisición de conocimiento. Madrid: Morata/Colofón.

Torres, R. M. (1999). "Qué modelo de formación para qué modelo educativo", en Aprender para el Futuro. Nuevo Marco de la Tarea Docente. Madrid: Santillana.

Southwell, M. (2006). "La tensión, desigualdad y escuela", en Igualdad y Educación: escritura entre dos orillas. Buenos Aires: Del estante editorial. Recuperado de: http://www.bnm.me.gov.

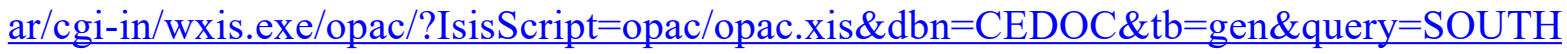
WELL,$\% 20$ MYRIAM \&operador $=$ AND\&src $=$ sug \& formato $=\&$ cantidad $=10 \&$ sala $=$

UNESCO (1998). "Proyecto Principal de Educación en América Latina y el Caribe". Boletín \# 45. Santiago de Chile.

Valdés, M. (2009). "Depósitos de sentido educativo y procesos de negociación del docente universitario frente a la renovación curricular". Tesis Doctoral. Guadalajara, Jalisco: ITESO.

(2013). "Depósitos de sentido educativo y los procesos de negociación de los docentes frente a la reforma curricular de una IES". Sinéctica 41. Recuperado de http://www.sinectica. iteso.mx/?seccion $=$ articulos\&lang $=$ es $\& \mathrm{id}=625$ depositos_de sentido_educatvo y_los_procesos_de_negociacion_de docente universitario.

Zavala, A. (2000). La práctica educativa. Cómo enseñar. Barcelona: Graó.

Recibido: 17/07/15

Dictaminado: 13/12/15

Corregido: 19/01/16

Aceptado: 19/01/16 